\title{
Chemometrics assisted spectrophotometric method for simultaneous determination of paracetamol and caffeine in pharmaceutical formulations
}

\author{
M. N. Uddin ${ }^{1}$, A. Mondol' ${ }^{2}$ M. M. Karim ${ }^{2 *}$, R. A. Jahan ${ }^{3}$ and A. A. Rana ${ }^{2}$ \\ ${ }^{1}$ Bangladesh Council of Scientific and industrial Research (BCSIR), Dhaka, Bangladesh \\ ${ }^{2}$ Department of Applied Chemistry and Chemical Engineering, University of Dhaka, Bangladesh \\ ${ }^{3}$ Materials Science \& Nanotechnology, Centre for Advanced Research in Sciences, University of Dhaka, Dhaka-1000, Bangladesh
}

Received: 24 June 2018

Revised: 26 July 2018

Accepted: 03 December 2018

DOI: $10.3329 /$ bjsir.v54i3.42673

\begin{abstract}
In this study, two chemometric techniques, partial least-square regression (PLSR) and artificial neural network (ANN) were developed and compared for the simultaneous assay of paracetamol (PCT) and caffeine (CAF) in pharmaceutical formulations by using spectrophotometric data. Six different concentrations of paracetamol and caffeine were considered to make mixture solutions of standard samples by using orthogonal experimental design (OED). UV spectra of these mixtures were recorded in the wavelength range of 205-300 $\mathrm{nm}$ versus a solvent blank and digitized absorbance was sampled at $1 \mathrm{~nm}$ intervals. Drug concentrations and instrumental spectra of 36 mixture solutions were used for model development and validation and finally 6 commercially available tablets were used to test the developed models. ANN shows better prediction efficiencies than that of PLSR with $\mathrm{R}^{2}$ value $99.28 \%$ for prediction and $99.13 \%$ for validation set. These two models were successfully applied to commercial pharmaceutical formulations, and it is found by ANN that the drugs contain 75 to $86 \%$ of paracetamol and 77 to $92 \%$ of caffeine of their label claim. Either of the proposed methods is simple and rapid and can be easily used in the quality assessment of drugs as an alternative analytical method.
\end{abstract}

Keywords: Paracetamol; Caffeine; Partial least-square regression; Artificial neural network; UV spectroscopy

\section{Introduction}

In Bangladesh, pharmaceutical sector is one of the most developed hi-tech sectors which are contributing to the country's economy. According to a report of the international management system (IMS) published in June 2015, the size of the pharmaceutical market of Bangladesh is estimated to be approximate 117 billion taka, with an annual growth rate of about $11.37 \%$. At present $97 \%$ of Bangladesh's need is produced locally. Bangladesh pharmaceutical industry export active pharmaceutical ingredients (APIs) and a wide range of pharmaceutical products covering all major therapeutic classes and dosage forms to 79 countries (Sultana, 2016). Now quality of the products becomes a great concern for manufacturers as well as consumers. Therefore, quality assessing techniques of these pharmaceutical products is one of the thirsty areas for research.
In the pharmaceutical formulations the combination of paracetamol (PCT) and caffeine (CAF) is widely given to patients as painkiller and antipyretic agent. Paracetamol, also known as acetaminophen, is a popularly used pain medication and medication to reduce fever over the country (Aghababian, 2010; Ahmad, 2010).

Chemically, paracetamol is 4-hydroxy acetanilide (Fig. 1). Paracetamol does not share the gastric side effects of other non-steroidal anti-inflammatory drugs (NSAIDs) as it has minor effect on cyclooxygenase in peripheral tissues. In addition, paracetamol affects blood platelets function and thereby increases blood clotting time (Rang et al., 2007).

Caffeine is a central nervous system (CNS) stimulant of the methylxanthine class (Nehlig et al., 1992). It is the world's 
Paracetamol
(1)<smiles>Cn1c(=O)c2c(ncn2C)n(C)c1=O</smiles>

Caffeine
Fig. 1. Chemical structures of paracetamol and caffeine

most widely consumed psychoactive drug, but unlike many other psychoactive substances it is legal and unregulated in nearly all parts of the world.

In order to achieve better curative effect and lower toxicity, it is very important to control the content of paracetamol and caffeine in pharmaceutical tablets. The quality control of dosage form preparations of drug requires reliable and quick analytical methods. Spectrophotometry as a simple, robust, quick and low cost method may be a good alternative if it is combined with multivariate calibration methods for determination of a complex mixture in pharmaceutical quality control (Dinc, 1999).

During the last decade, several research work have been conducted for quantification of ingredients in drugs (Safavi and Tohidi, 2007; Tavallali and Sheikhaei, 2009; Tavallali et al., 2011) mostly based on chromatographic techniques (Bebawy and El-Kousy, 1999; Prodan et al., 2003; Tsvetkova et al., 2012; Issa et al., 2012; Bhosale et al., 2012; Chandra and Dutt, 2013; Soponar et al., 2013; Redasani et al., 2013; Belal et al., 2014; Khalid et al., 2015) . A few initiatives with spectroscopic techniques have been reported in the literature (Rogers and Adams, 1999; Ortega-Barrales et al., 2002; Delvadiya et al., 2011; Hajian and Soltaninezhad, 2013). In some studies, results of spectroscopic methods are compared with those of chromatographic techniques (Dinc, 1999). Spectrophotometric determination of paracetamol and caffeine in pharmaceutical formulation using chemometric techniques has rarely been reported (Luna and Pinho, 2014; Santosh and Shreeyash, 2016).

UV/Visible spectrophotometry is by far the instrumental technique of choice of industrial laboratories, owing mainly to simplicity, often demanding low cost equipment. Simultaneous quantitative analysis of pharmaceuticals containing multi-active compounds is difficult to perform by classical spectrophotometric method. In recent years, multivariate chemometric methods seem to be the techniques showing a best performance in terms of complex mixture solution (Israt et al., 2016; Karim et al., 2015). In UV spectroscopic analysis, absorbance of light by certain drugs against wave length or wave number is the main consideration for spectral data. In each spectrum there are huge numbers of absorbance value for each wave point. Each wave point or data point is considered as spectroscopic variable. These variables are huge in number and are mutually correlated. In this situation we cannot use ordinary least square (OLS) method as problem of singularity will exist. So, we fit partial least squares regression (PLSR) and artificial neural network (ANN), and compare their prediction efficiencies in the study.

The objective of the study is to suggest a cost effective method for rapid quantification of paracetamol and caffeine in commercially available such drugs on the basis of chemometric techniques on UV-visible spectroscopic data as part of their quality assessment.

\section{Materials and methods}

\section{Apparatus and software}

Shimadzu UV-visible spectrometer (Model: UV-1800, Shimadzu, Kyoto, Japan), equipped with $1 \mathrm{~cm}$ matched quartz cells was used for spectrometric measurements. The system software UV Probe 2.34 of the instrument was used for obtaining the spectra. In this research SPSS Statistics 22.0 has been used for experimental design and MATLAB 2014a for developing artificial neural network (ANN). The Unscrambler ${ }^{\circledR} \mathrm{X}$ of its version 10.3 has been used for partial least-squares regression (PLSR).

\section{Standard sample}

Active pharmaceutical ingredients paracetamol and caffeine were kindly supplied by Acme Laboratories limited, Kallayanpur, and Dhaka, Bangladesh. All the materials used in spectrophotometric analysis were of analytical reagent grade.

\section{Pharmaceutical tablet formulation}

Six different commercial pharmaceutical formulations Ace $^{\circledR}$ Plus tablet produced by Square, Napa ${ }^{\circledR}$ Extra tablet manufactured by Beximco Pharma, Fast Plus tablet produced by Acme, Pyrenol tablet produced by Delta Pharma Limited, Panadol Extra tablet formulated by GlaxoSmithKline, Reset Plus tablet produced by Incepta containing $500 \mathrm{mg}$ paracetamol and $65 \mathrm{mg}$ caffeine were purchased from local resources and analyzed by the proposed chemometric methods. Results are presented by hiding company and product names. 


\section{Selection of a common solvent}

After assessing the solubility of drugs in different solvents methanol has been selected as common solvent for preparing the solutions. Methanol was purchased from Sigma-Aldrich Chemie Gmbh (Munich, Germany).

\section{Standard stock solution preparation}

Stock solution of paracetamol and caffeine were prepared by taking about $10 \mathrm{mg}$ of each working standards. The content transferred to two separate $100 \mathrm{~mL}$ volumetric flask and dissolved in methanol. The volume was then made up to the mark with methanol. The final solution had concentration of $100 \mu \mathrm{g} / \mathrm{mL}$ for each of the two drugs that were used to set up the calibration set. The above standard stock solutions of paracetamol and caffeine were used to obtain the linear range of $8.0-40.0 \mu \mathrm{g} / \mathrm{mL}$ and $5.0-36.0 \mu \mathrm{g} / \mathrm{mL}$ for paracetamol and caffeine respectively by appropriate dilution. Six different concentrations of paracetamol $(8.0,15.0,25.0,30.0,35.0$ and $40.0)$ and caffeine $(5.0,8.0,10.0,15.0,20.0$ and 36.0) were considered to make mixture solutions from standards by the orthogonal experimental design (OED) (Table 1). 36 solutions were prepared where correlation of concentrations of paracetamol and caffeine are zero.

Table I. Mixing proportion of paracetamol and caffeine by OED

\begin{tabular}{cllcll}
\hline $\begin{array}{c}\text { Sample } \\
\text { ID }\end{array}$ & $\begin{array}{c}\text { Paracetamol } \\
(\mathrm{ppm})\end{array}$ & $\begin{array}{c}\text { Caffeine } \\
(\mathrm{ppm})\end{array}$ & $\begin{array}{c}\text { Sample } \\
\text { ID }\end{array}$ & $\begin{array}{c}\text { Paracetamol } \\
(\mathrm{ppm})\end{array}$ & $\begin{array}{c}\text { Caffeine } \\
(\mathrm{ppm})\end{array}$ \\
\hline 1 & 8 & 36 & 19 & 25 & 8 \\
2 & 8 & 10 & 20 & 40 & 8 \\
3 & 30 & 36 & 21 & 30 & 15 \\
4 & 15 & 10 & 22 & 25 & 20 \\
5 & 35 & 10 & 23 & 35 & 5 \\
6 & 40 & 15 & 24 & 30 & 20 \\
7 & 8 & 8 & 25 & 40 & 10 \\
8 & 25 & 10 & 26 & 15 & 15 \\
9 & 35 & 20 & 27 & 40 & 20 \\
10 & 15 & 20 & 28 & 40 & 5 \\
11 & 25 & 5 & 29 & 30 & 8 \\
12 & 35 & 36 & 30 & 8 & 5 \\
13 & 25 & 36 & 31 & 8 & 15 \\
14 & 30 & 5 & 32 & 8 & 20 \\
15 & 35 & 15 & 33 & 35 & 8 \\
16 & 40 & 36 & 34 & 15 & 8 \\
17 & 30 & 10 & 35 & 25 & 15 \\
18 & 15 & 5 & 36 & 15 & 36 \\
\hline
\end{tabular}

In total, $42(36+6)$ samples were used in the study. Drug concentration and instrumental spectra of 36 mixture solutions were used for model development and validation and finally six (6) commercially available tablets were used to test developed models.

\section{Preparation of standard solutions for multivariate analysis}

To develop the chemometric calibration, thirty six preparations (calibration set) of standard solutions containing mixture of paracetamol and caffeine were prepared. In this procedure, at first, appropriate volume of standard stock solutions of paracetamol and caffeine in the concentration ranges between 8.0-40.0 $\mu \mathrm{g} / \mathrm{mL}$ for paracetamol and 5.0-36.0 $\mu \mathrm{g} / \mathrm{mL}$ for caffeine were added in separate $10 \mathrm{ml}$ flasks using micropipette (operating range: $60 \mu \mathrm{L}-1000 \mu \mathrm{L}$ ). Then the solutions were diluted to $10 \mathrm{ml}$ with methanol. After that a vortex mixer was used to mix the solutions of paracetamol and caffeine uniformly with the solvent for each of the thirty six preparations. All the solutions were prepared freshly, stored in room temperature and protected from light. UV spectra of these mixtures were recorded in the wavelength range of 205-300 nm versus a solvent blank and digitized absorbance was sampled at $1 \mathrm{~nm}$ intervals.

\section{Chemometric methods}

Analysis of multivariate data plays a key role in chemometrics. Multivariate analysis often starts out with data involving a substantial number of correlated variables. In majority of chemometric data matrix, number of variables is higher than number of cases. Both of the situations create problems in analyzing the data. In this situation ordinary least Square regression (OLSR) cannot be used. As alternative, two statistical techniques partial least square regression (PLSR) and artificial neural networks (ANN) were fitted with the spectroscopic data and compared their prediction efficiencies.

\section{Partial least-square regression (PLSR)}

Partial least squares regression (PLSR) is a popular method for soft modeling in research and industrial applications. PLS regression combines features from principal component analysis and multiple regressions. Its goal is to predict or analyze a set of dependent variables from a set of independent variables or predictors. This prediction is achieved by extracting from the predictors a set of orthogonal factors called 'latent variables' which have the best predictive power. By contrast, PLS regression finds components from independent variables that are also relevant for dependent variable. Specifically, PLS regression searches for a set of components (called latent vectors) that performs a simultaneous decomposition of and with the constraint that these components explain as much as possible of the covariance between and. It is followed by a regression step where the decomposition of is used to predict . 


\section{Artificial neural network (ANN)}

An ANN, often just called a neural network, is a mathematical model inspired by biological neural networks. Neural networks are used to model complex relationships between inputs and outputs or to find patterns in data. ANNs are powerful chemometric methods as they do not need any model problems of non-linear systems. ANN has been applied in almost every aspect of analytical chemistry over the past two decades, although most applications are in the development stage. ANNs are useful tools for drug safety and quality analyses, which include modeling for this predicting food safety, interpreting spectroscopic data, and predicting physical, chemical, functional and sensory properties of various food products during processing and distribution. ANNs hold a great deal of promise for modeling complex tasks in process control and simulation and in applications of machine perception including machine vision and electronic nose for drug safety and quality control. In practical, Levenberg-Marquardt back-propagation neural network has used in the present study. Number of hidden neurons is 10 and the sigmoid activation function is used in each step.

Six fold cross-validation has been used in all cases to minimize the risk of overfitting the calibrations when evaluating calibration accuracy.

\section{Results and discussion}

Fig. 2 displays the UV absorption spectra of PCT and CAF together with their mixture. In the presence of the overlapping spectra of two compounds in the spectral range $205-300 \mathrm{~nm}$ determination of the related compounds in samples is not possible by using classical spectrophotometric approaches. We have focused mainly on the quantitative resolution of the binary mixtures of PCT and CAF by using PLSR and ANN chemometric approaches without any separation step

From principal component analysis (PCA) it can be shown that first principal component (PC1) express $78 \%$ of the variation whereas PC2 express $21 \%$ of the total variation. Samples are independently scattered. Correlation loadings explained that some of the data are positively correlated and others are negatively correlated and there is no outlier in the samples considered in the study.

Explained variance plot (Fig. 3) predicts that highest explained variance is found with 2 PCs. First two principal components express $98.72 \%$ of total variations for calibration data and $98.46 \%$ for validation data.

From partial least-square regression (PLSR) it can be shown that the first factor (Factor-1) express $85 \%$ and $83 \%$ of the variation for PCT and $80 \%$ and $49 \%$ of the variation for $\mathrm{CAF}$ whereas the second factor (Factor-2) express $14 \%$ and $16 \%$ for PCT and $19 \%$ and $50 \%$ for CAF of the total variation. Explained variance plots for PCT and CAF predict that highest explained variance is found with 2 factors. These two factors express $99 \%$ of total variations for calibration and validation of data.

In order to measure the performance of neural network several tools are used. In this study root mean squared error (RMSE) for prediction and coefficient of determination $\left(\mathrm{R}^{2}\right)$ for prediction

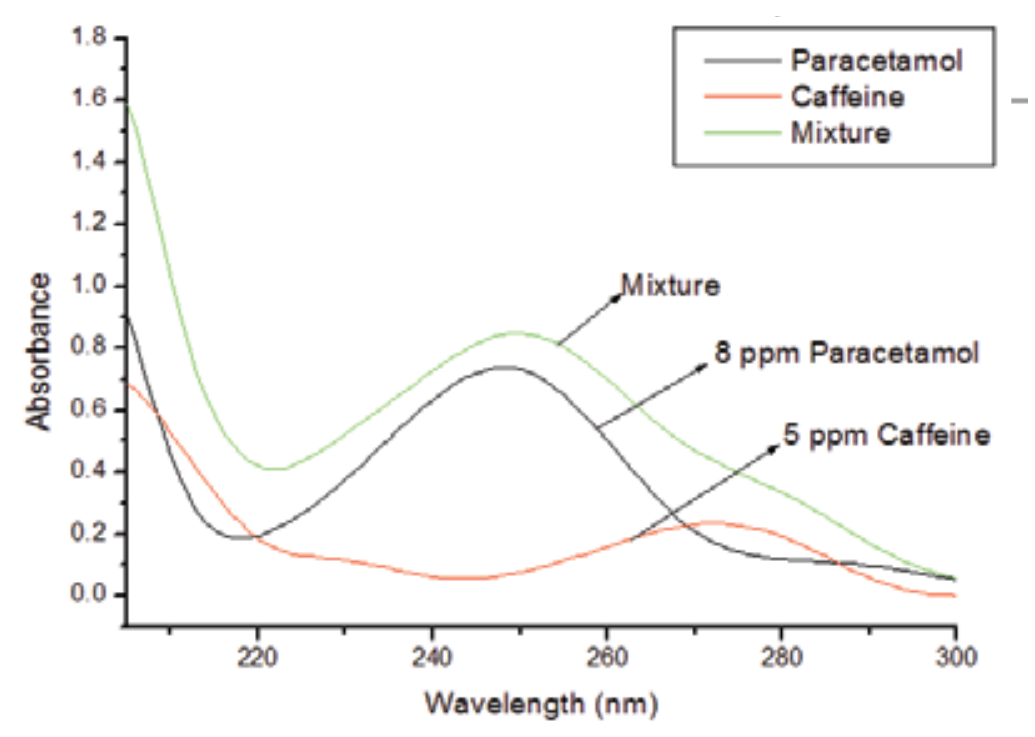

Fig. 2. Spectra of $8 \mathrm{ppm}$ paracetamol, $5 \mathrm{ppm}$ caffeine and their mixtures 
and classification were calculated. Root mean squared error is the square root of average squared difference between outputs and targets. Lower values are better. Zero means no error.

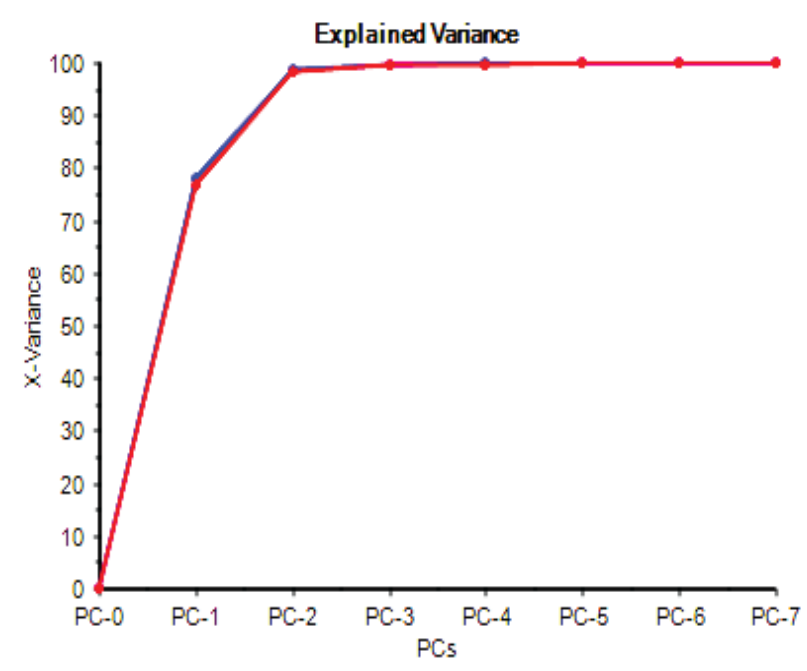

Fig. 3. Explained variance plot

Plotted points and model parameters in blue colour represent the results are from calibration set and those of red colour are from the cross-validation datasets (Fig. 3-5).

Two models PLSR and ANN have been developed for prediction of paracetamol and caffeine and their prediction efficiencies have been compared. In order to develop the models $75 \%$ samples have been used for calibration and $25 \%$ of them are for validating the models. Prediction efficiencies expressed in terms of root mean square error (RMSE) and coefficient of determination $\left(\mathrm{R}^{2}\right)$ are shown in the Table 2. Results show that both of the models are very good at predicting concentration of paracetamol and caffeine in their calibration and validation stages.

For paracetamol, ANN shows better prediction efficiencies than that of PLSR with $\mathrm{R}^{2}$ value $99.28 \%$ for prediction and $99.13 \%$ for validation set. Similar results can be noticed for caffeine by ANN.

Both ANN and PLSR show extraordinary performance for prediction of paracetamol and caffeine with calibration and validation datasets $\left(\mathrm{R}^{2} \approx 0.99\right)$. So, both of them could be recommended as calibration techniques for quantification of these essential components in pharmaceutical formulations.

In order to access the applicability of the proposed PLSR and ANN methods to the analysis of the real samples, they were applied to the determination of these drugs in pharmaceutical formulations. Six replicate measurements for each real sample were made. The percentage recoveries and relative standard deviations are indicated in the Table 3. The good agreement between these results and the label claims indicate the successful applicability of the proposed procedures for the simultaneous determination of paracetamol and caffeine in real samples.

By ANN, it is found that about 86 percent paracetamol is available in the tablets of pharmaceutical company-A of their label claimed value and by PLSR this is 86.58 percent. For caffeine these percentages are 84.11 and 79.24 by ANN and

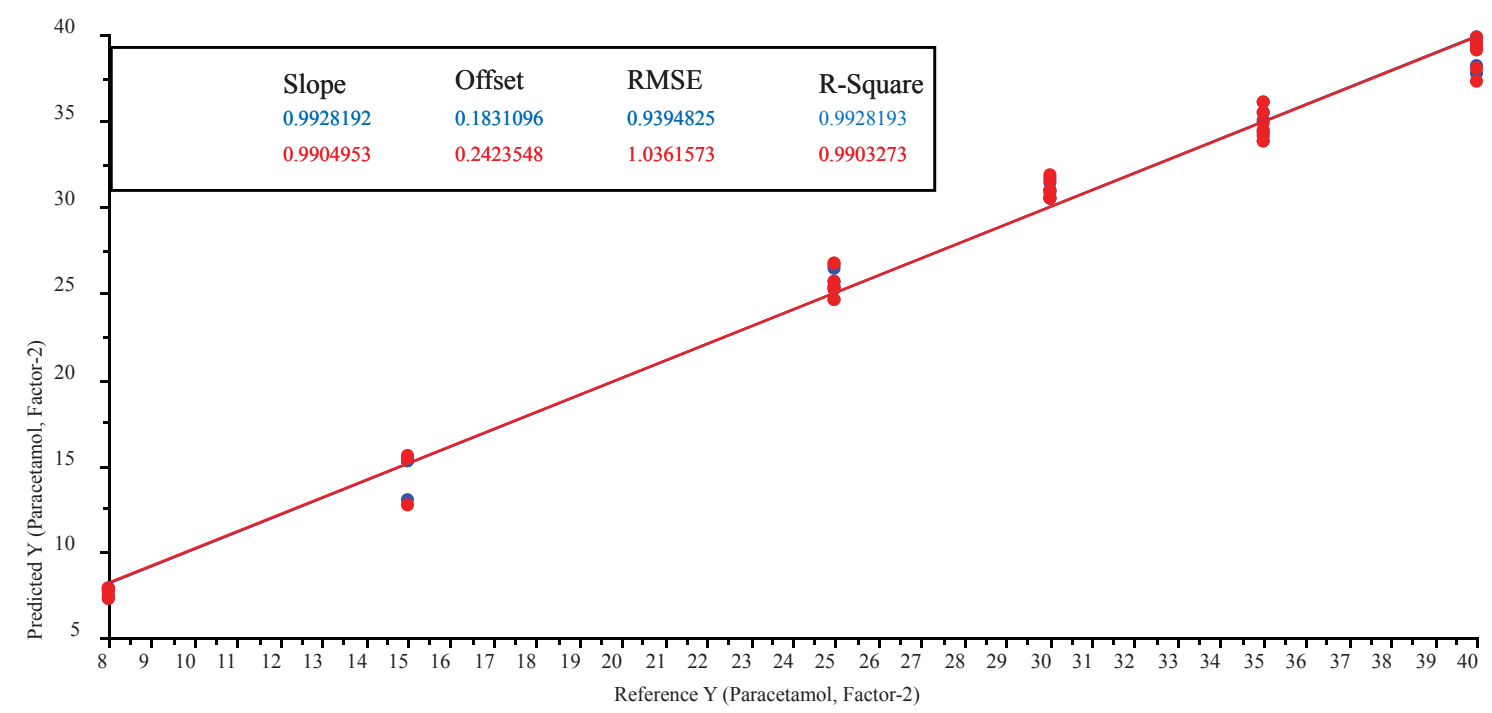

Fig. 4. Partial Least Square Regression (PLSR) model for prediction of Paracetamol 
PLSR respectively. Tablets of all other companies provide about 75 to 86 percent paracetamol and 77 to 92 percent caffeine from ANN. Almost similar results are noticed from PLSR both for paracetamol and caffeine.

In the study, two chemometric models were successfully developed for quantification of paracetamol and caffeine respectively in pharmaceutical formulation by PLSR and ANN with UV-spectroscopic data. We found them to be simple, precise, accurate, rapid and economical methods for drugs although ANN shows slightly better results than PLSR in this regard. High percentage of recovery shows that the methods are free from interference of the excipients used in the commercial formulation. Results also reveal that the developed methods can be applied for a routine analysis and quantitative control of mixtures and commercial preparations containing these two drugs. It is evident from the results that commercially available drugs whose main ingredients are paracetamol and caffeine do not contain as much as the manufacturing companies claim in their labels.

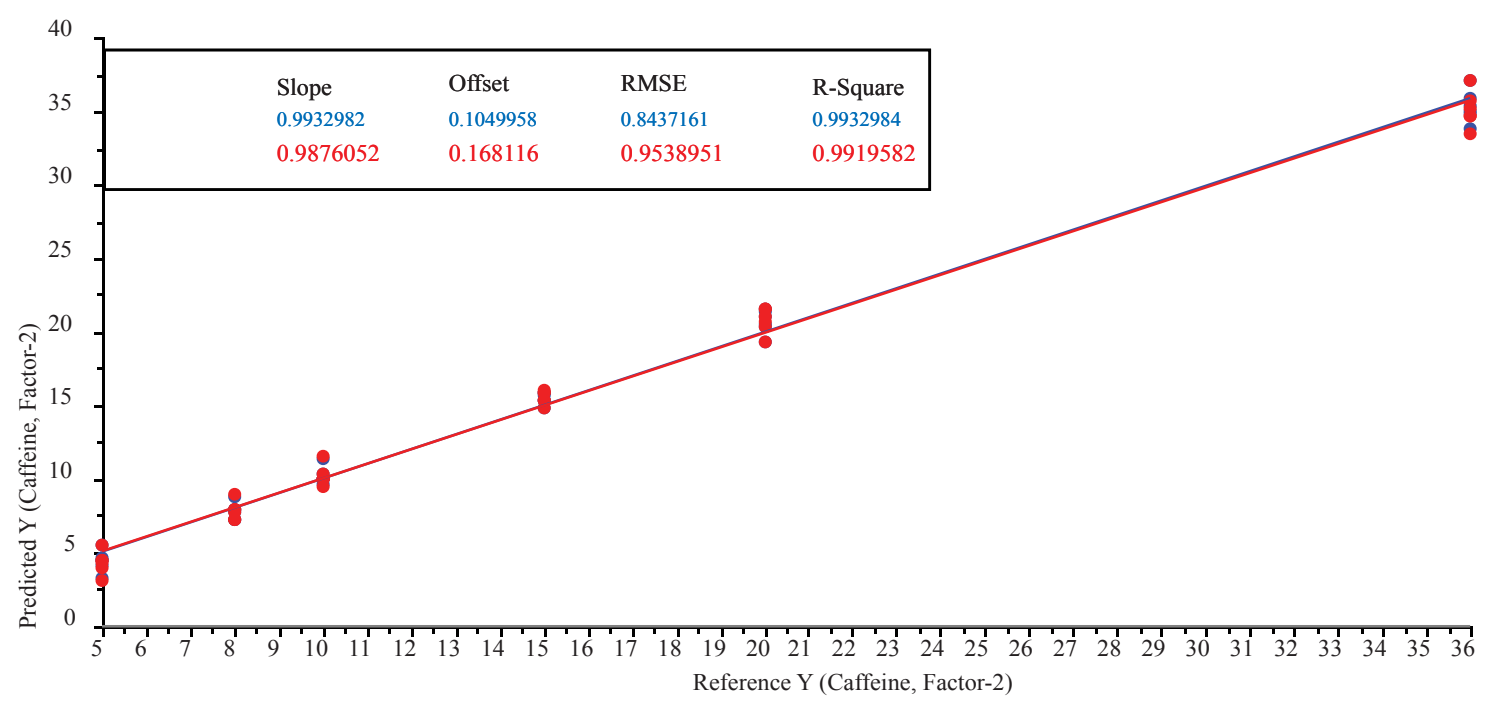

Fig. 5. Partial Least Square Regression (PLSR) model for prediction of Caffeine

their simultaneous determination. Both of these methods were successfully validated and found suitable for quality control of such drugs in available in the market. However, it is evident from the results of the study that ANN model is more accurate than PLSR model for the quantification of paracetamol and caffeine in pharmaceutical formulation.

\section{Conclusion}

It can be found that both ANN and PLSR are efficient for determination of paracetamol and caffeine in commercial
This proposed method could be used by pharmaceutical companies to ensure the quality of the product with minimum testing time and cost. Moreover, drug administration or who are working responsible for the quality of the product can use this method for the assessment of the quality of the drug. Finally, individual consumer can also get the tested result conscious from any laboratory which has UV-spectrophotometer and the proposed method.

Table II. Comparison of prediction efficiencies of ANN and PLSR

\begin{tabular}{llcccc}
\hline \multirow{2}{*}{ Sample } & \multirow{2}{*}{ Dataset } & \multicolumn{2}{c}{ ANN } & \multicolumn{2}{c}{ PLSR } \\
\cline { 3 - 6 } Paracetamol & Calibration & 0.5287 & 0.9996 & 0.9395 & 0.9928 \\
& Validation & 0.9644 & 0.9949 & 1.0366 & 0.9903 \\
\multirow{2}{*}{ Caffeine } & Calibration & 0.4727 & 0.9994 & 0.8437 & 0.9933 \\
& Validation & 0.3199 & 0.9993 & 0.9539 & 0.9919 \\
\hline
\end{tabular}


Table III. Quantification of paracetamol (PCT) and caffeine (CAF) in commercial tablets and comparison with label claim

\begin{tabular}{|c|c|c|c|c|c|c|c|c|c|c|}
\hline \multirow[t]{3}{*}{ Manufacturer } & \multicolumn{2}{|c|}{$\begin{array}{l}\text { Label Claim } \\
\text { (mg) }\end{array}$} & \multicolumn{2}{|c|}{$\begin{array}{l}\text { PCT } \\
(\mathrm{mg})\end{array}$} & \multicolumn{2}{|c|}{$\begin{array}{l}\text { CAF } \\
(\mathrm{mg})\end{array}$} & \multicolumn{4}{|c|}{ \% Label Claim } \\
\hline & \multirow{2}{*}{ PCT } & \multirow{2}{*}{ CAF } & \multirow{2}{*}{ ANN } & \multirow{2}{*}{ PLSR } & \multirow{2}{*}{ ANN } & \multirow{2}{*}{ PLSR } & \multicolumn{2}{|c|}{ PCT } & \multicolumn{2}{|c|}{$\mathrm{CAF}$} \\
\hline & & & & & & & ANN & PLSR & ANN & PLSR \\
\hline $\begin{array}{l}\text { Company -A } \\
(\text { Mean } \pm \text { SD) }\end{array}$ & 500 & 65 & $\begin{array}{r}430.54 \\
\pm 13.04\end{array}$ & $\begin{array}{l}432.93 \\
\pm 9.74\end{array}$ & $\begin{array}{l}54.68 \\
\pm 3.38\end{array}$ & $\begin{array}{l}51.51 \\
\pm 2.12\end{array}$ & $\begin{array}{l}86.10 \\
\pm 2.61\end{array}$ & $\begin{array}{l}86.58 \\
\pm 1.95\end{array}$ & $\begin{array}{l}84.11 \\
\pm 5.20\end{array}$ & $\begin{array}{l}79.24 \\
\pm 3.26\end{array}$ \\
\hline $\begin{array}{r}\text { Company -B } \\
(\text { Mean } \pm \text { SD) }\end{array}$ & 500 & 65 & $\begin{array}{l}423.11 \\
\pm 9.67\end{array}$ & $\begin{array}{l}429.42 \\
\pm 4.63\end{array}$ & $\begin{array}{l}59.76 \\
\pm 2.06\end{array}$ & $\begin{array}{l}52.75 \\
\pm 1.30\end{array}$ & $\begin{array}{l}84.62 \\
\pm 1.93\end{array}$ & $\begin{array}{l}85.88 \\
\pm 0.93\end{array}$ & $\begin{array}{l}91.94 \\
\pm 3.17\end{array}$ & $\begin{array}{l}81.16 \\
\pm 2.00\end{array}$ \\
\hline $\begin{array}{r}\text { Company -C } \\
(\text { Mean } \pm \text { SD) }\end{array}$ & 500 & 65 & $\begin{array}{l}401.37 \\
\pm 9.76\end{array}$ & $\begin{array}{l}423.86 \\
\pm 6.39\end{array}$ & $\begin{array}{l}51.81 \\
\pm 2.85\end{array}$ & $\begin{array}{l}51.45 \\
\pm 1.41\end{array}$ & $\begin{array}{l}80.27 \\
\pm 1.95\end{array}$ & $\begin{array}{l}84.77 \\
\pm 1.27\end{array}$ & $\begin{array}{l}79.71 \\
\pm 4.38\end{array}$ & $\begin{array}{l}79.15 \\
\pm 2.16\end{array}$ \\
\hline $\begin{array}{r}\text { Company -D } \\
(\text { Mean } \pm \text { SD) }\end{array}$ & 500 & 65 & $\begin{array}{l}424.09 \\
\pm 13.24\end{array}$ & $\begin{array}{l}431.35 \\
\pm 9.11\end{array}$ & $\begin{array}{l}55.09 \\
\pm 6.41\end{array}$ & $\begin{array}{l}49.15 \\
\pm 3.24\end{array}$ & $\begin{array}{l}84.84 \\
\pm 2.65\end{array}$ & $\begin{array}{l}86.26 \\
\pm 1.82\end{array}$ & $\begin{array}{l}84.75 \\
\pm 9.86\end{array}$ & $\begin{array}{l}75.62 \\
\pm 4.98\end{array}$ \\
\hline $\begin{array}{r}\text { Company -E } \\
(\text { Mean } \pm \text { SD) }\end{array}$ & 500 & 65 & $\begin{array}{l}393.03 \\
\pm 13.36\end{array}$ & $\begin{array}{l}409.42 \\
\pm 9.63\end{array}$ & $\begin{array}{l}50.18 \\
\pm 1.01\end{array}$ & $\begin{array}{l}46.22 \\
\pm 1.81\end{array}$ & $\begin{array}{l}78.60 \\
\pm 2.67\end{array}$ & $\begin{array}{l}81.88 \\
\pm 1.93\end{array}$ & $\begin{array}{l}77.20 \\
\pm 1.55\end{array}$ & $\begin{array}{l}71.99 \\
\pm 2.79\end{array}$ \\
\hline $\begin{array}{r}\text { Company -F } \\
(\text { Mean } \pm \text { SD) }\end{array}$ & 500 & 65 & $\begin{array}{l}374.27 \\
\pm 18.19\end{array}$ & $\begin{array}{l}394.01 \\
\pm 16.45\end{array}$ & $\begin{array}{l}50.15 \\
\pm 3.35\end{array}$ & $\begin{array}{l}47.18 \\
\pm 3.69\end{array}$ & $\begin{array}{l}74.85 \\
\pm 3.64\end{array}$ & $\begin{array}{l}78.79 \\
\pm 3.34\end{array}$ & $\begin{array}{l}77.14 \\
\pm 5.16\end{array}$ & $\begin{array}{l}72.58 \\
\pm 5.69\end{array}$ \\
\hline
\end{tabular}

\section{Acknowledgement}

The authors acknowledge the technical supports provided by the department of Applied Chemistry and Chemical Engineering, University of Dhaka, Materials Science \& Nanotechnology, Centre for Advanced Research in Sciences (CARS), University of Dhaka and Bangladesh Council of Scientific and Industrial Research (BCSIR), Dhaka-1205, Bangladesh.

\section{References}

Aghababian RV (2010), Essentials of emergency medicine. Jones \& Bartlett Publishers, pp 814.

Ahmad J (2010), Hepatology and transplant hepatology: A case based approach, Springer, pp194.

Bebawy LI and El-Kousy NM (1999), Simultaneous determination of some multicomponent dosage forms by quantitative thin layer chromatography densitometric method, J. Pharm. Biomed. Anal. 20: 663-70.

Belal TS, Khamis FE, Fawzy A, Yazbi EI and Hamdy MA (2014), High performance liquid chromatographic determination of the ternary mixture of caffeine, dipyrone and drotaverine hydrochloride in tablets dosage form, J. Appl. Pharm. Sci. 4: 033-039.
Bhosale D, Pratima A and Nikalje G (2012), Development and validation of RP-chromatography for simultaneous determination of paracetamol, caffeine, ergotamine and prochlorperazine in tablets, Asian J. Pharm. Sci. 7: 364-370.

Chandra R and Dutt KS (2013), Quantitative determination of paracetamol and caffeine from formulated tablets by reversed phase-HPLC separation technique, Int. J. Chromatogr. Sci. 3: 31-34.

Delvadiya K, Kimbahune R, Kabra P, Sunil K and Patel P (2011), Spectrophotometric simultaneous analysis of paracetamol, propyphenazoe and caffeine in tablet dosage forms, Int. J. Pharm. Pharm. Sci. 3: 170-174.

Dinç E (1999), A comparative study of the ratio spectra derivative spectrophotometry, Vierordt's method and high-performance liquid chromatography applied to the simultaneous analysis of caffeine and paracetamol in tablets, J. Pharm. Biomed. Anal. 21: 723-730.

Hajian R and Soltaninezhad A (2013), The spectrophotometric multicomponent analysis of a ternary mixture of paracetamol, aspirin, and caffeine by the double divisor-ratio spectra derivative method, J. Spectrosc. 2013: 01-07. DOI: org/10.1155/ 2012/621263 
Israt SS, Uddin MN, Jahan RA and Karim MM (2016), Simultaneous determination of furosemide and spironolactone in pharmaceutical formulations by spectrophotometric method using principal component regression, Bangladesh J. Sci. Ind. Res. 51: 297-306.

Issa YM, Hassouna MEM and Zayed AG (2012), Simultaneous determination of paracetamol, caffeine, domperidone, ergotamine tartrate, propyphenazone, and drotaverine HCL by high performance liquid chromatography, J. Liq. Chrom. Relat. Tech. 35: 33-39. DOI:org/10.1080/10826076.2011.629387

Khalid KM, Kayesh R, Islam MH, Rahman A and Islam MR (2015), A stability-indicating HPLC-PDA method for simultaneous determination of paracetamol, caffeine, ibuprofen and their degradation products in solid dosage forms, Am. J. PharmTech. Res. 5: 348-360.

Karim MM, Karim SFE, Rana AA, Masum SM, Mondol A and Israt SS (2015), ATR-FTIR spectroscopy and chemometric techniques for the identification of edible vegetable oils, Bangladesh J. Sci. Ind. Res. 50: 233-240.

Luna AS and Pinho JSA (2014), Determination of paracetamol and ibuprofen in tablets and urine using spectrofluorimetric determination coupled with chemometric tools, Austin J. Anal. Pharm. Chem. 1: 01-07.

Nehlig A, Daval JL and Debry G (1992), Caffeine and the central nervous system: mechanisms of action, biochemical, metabolic and psychostimulant effects, Brain Res. Brain Res. Rev. 17: 139-70.

Ortega-Barrales P, Padilla-Weigand R and Molina-Díaz A (2002), Simultaneous determination of paracetamol and caffeine by flow injection-solid phase spectrometry using $\mathrm{C}_{18}$ silica gel as a sensing support, Anal. Sci. 18:1241-6. DOI:org/10.2116/analsci.18.1241

Prodan M, Gere-Paszti E, Farkas O and Forgacs E (2003), Validation and simultaneous determination of paracetamol and caffeine in pharmaceutical formulations by RP- HPLC, Chemia Analityczna 48: 901-907.

Redasani VK, Gorle AP, Badhan RA, Jain PS and Surana S (2013), Simultaneous determination of chlorpheniramine maleate, phenylephrine hydrochloride, paracetamol and caffeine in pharmaceutical preparation by RP-HPLC, Chem. Ind. Chem. Eng. Q. 19: 57-65. DOI:10.2298/ CICEQ120302042R
Rogers LJ and Adams MJ (1999), Simultaneous determination of paracetamol, aspirin and caffeine in tablet formulations using factor analysis, Anal. Commun. 33: 401-402. DOI:10.1039/ AC9963300401

Safavi A and Tohidi M (2007), Simultaneous kinetic determination of levodopa and carbidopa by H-point standard addition method, J. Pharm. Biomed. Anal. 44: 313-318.

Santosh VG and Shreeyash RT (2016), Chemometric-assisted UV-spectrophotometric method for simultaneous estimation of paracetamol, chlorzoxazone and ibuprofen in multicomponent formulation, AshEsE J. Pharm. 1: 001-008.

Soponar F, Staniloae D, Moise G, Szaniszlo B and David V (2013), Simultaneous determination of paracetamol, propyphenazone and caffeine from pharmaceutical preparations in the presence of related substances using a validated HPLC-DAD method, Rev. Roum. Chim. 58: 433-440.

Sultana J (2016), Future prospects and barriers of pharmaceutical industries in Bangladesh, Bangladesh Pharmaceutical Journal 19: 53-57.

Tavallali H and Sheikhaei M (2009), Simultaneous kinetic determination of paracetamol and caffeine by H-point standard addition method, Afr. J. Pure Appl. Chem. 3: 11-19.

Tavallali H, Zareiyan SF and Naghian M (2011), An efficient and simultaneous analysis of caffeine and paracetamol in pharmaceutical formulations using TLC with a fluorescence plate reader, J. AOAC Int. 94: 1094-9.

Tsvetkova B, Kostova B, Pencheva I, Zlatkov A, Rachev D and P Peikov (2012), Validated LC method for simultaneous analysis of paracetamol and caffeine in model tablet formulation, Int. J. Pharm. Pharm. Sci. 4: 680-684. 